ISSN : $2406-7415$

E-ISSN : $2655-9919$

JURNAL AKUNTANSI DAN BISNIS KRISNADWIPAYANA

DOI: http://dx.doi.org/10.35137/jabk.v8i1.486

Volume 8 Nomor 1 (Januari - April) 2021

\title{
PENGARUH SOSIALISASI PERPAJAKAN TERHADAP NIAT UNTUK MEMATUHI KEWAJIBAN PERPAJAKAN CALON WAJIB PAJAK DENGAN KESADARAN PAJAK SEBAGAI VARIABEL INTERVENING
}

\author{
Sahrul Ramadhan ${ }^{1)}$ \\ Fakultas Ekonomi Universitas Sarjanawiyata Tamansiswa Yogyakarta \\ Jalan Kusumanegara No. 121 Yogyakarta \\ Handphone Penulis : 083854935309 ,e-mail: ${ }^{3}$ sahrulramadhanustyk17@gmail.com \\ Dewi Kusuma Wardani ${ }^{2)}$ \\ Fakultas Ekonomi Universitas Sarjanawiyata Tamansiswa Yogyakarta \\ Jalan Kusumanegara No. 121 Yogyakarta \\ E-mail: dewifeust@gmail.com \\ Anita Primastiwi ${ }^{3)}$ \\ Fakultas Ekonomi Universitas Sarjanawiyata Tamansiswa Yogyakarta \\ Jalan Kusumanegara No. 121 Yogyakarta \\ E-mail: anita.primas@ustjogja.ac.id
}

\begin{abstract}
This study aims to reveal whether the socialization of taxation to high school students in Yogyakarta has an effect on their intention to comply with taxes through tax awareness. This research data uses direct / primary data. The sampling method is convenience sampling. The data analysis technique is path analysis with the socialization of taxation being the independent variable and the intention to comply with taxes as the dependent variable, and tax awareness being the intervening variable. The results of the analysis conclude that tax socialization has a positive effect on tax awareness and tax compliance intentions, tax awareness also has a positive effect on tax compliance intentions, and tax socialization also has a positive effect on tax compliance intentions through tax awareness. The implication of this research proves that the socialization of taxation is one of the elements that has an important role in the growth of tax compliance intentions within prospective taxpayers.
\end{abstract}

Keywords: Tax Socialization; Tax Awareness; Tax Compliant Intent; Prospective Taxpayers

\section{PENDAHULUAN}

Pajak ialah iuran terhadap negara yang sifatnya terhutang kepada yang wajib membayar, sesuai dengan aturan perundangundangan yang tidak memperoleh manfaat langsung, dan ditujukan untuk membiayai pengeluaran negara (Yulia et al., 2020).
Kemauan wajib pajak untuk membayar pajaknya menjadi perihal penting untuk meningkatkan penerimaan pajak tersebut (Suyadi \& Sunarti, 2016). Sebab sumber pemasukan terbesar negara adalah pajak yang ditujukan agar rakyat sejahtera, seperti memberikan layanan yang baik, hukum yang 
setimpal serta menjaga keamanan dan kedamaian negara (Yulia et al., 2020).

Tabel 1. Realisasi perolehan pajak tahun 2019

Sumber: krjogja.com (2019)
Berdasarkan tabel 1 di atas bahwa
penerimaan pajak tahun 2019
di DIY belum sesuai target, dimana
ditargetkan sebesar Rp 6,1 triliun di tahun
2019, namun hanya Rp 1,8 triliun yang
terealisasi. Mengacu pada tabel 1 di atas
perolehan pajak nasional di tahun 2019 juga
belum mencapai taget, dimana yang
ditargetkan Rp 1.577 triliun, tetapi hanya
terealisasi sebesar Rp 500 triliun. Walaupun
penerimaan pajak di DIY belum setara
nasional, tetapi jika ditinjau melalui segi
peningkatan kinerja pajak, ternyata tidak
terpaut jauh dari persentase peningkatan
nasional, dimana kinerja perolehan pajak di
DIY naik 2,38\%, sedangkan nasional 2,85\%
diperiode yang bersamaan (krjogja.com,
2019).

Mengacu pada fenomena ini ternyata kepatuhan pajak masih sangat perlu untuk dibenahi, sebab merupakan faktor utama yang mempengaruhi penerimaan pajak (Purba, 2016). Hal ini juga dikatakan Wardani \& Wati (2018) bahwa unsur eksternal yang mempunyai pengaruh terhadap kepatuhan pajak ialah sosialisasi perpajakan.

Sosialisasi/penyuluhan ini adalah upaya membagikan pengertian tentang perpajakan untuk merubah pengetahuan/pemahaman, kemampuan, dan juga sikap masyarakat supaya terdorong mampu mengerti, menyadari, peduli serta berpartisipasi dalam memenuhi pajak (Sari \& Saryadi, 2018).

Mengatasi permasalahan ini, perlu dilakukan peningkatan kinerja penerimaan pajak di DIY melalui sosialisasi perpajakan.
Volume 8 Nomor 1 (Januari - April) 2021

Sosialisasi yang ditujukan tidak harus kepada para wajib pajak terdaftar, namun juga kepada siswa SMA atau sederajat, sebab setelah lulus nanti siswa akan menjadi bagian dari masyarakat dalam melakukan kegiatan ekonomi (Septiyani \& Putranti, 2013).

Sosialisasi perpajakan kepada siswa didik perlu diberikan, bisa melalui penyuluhan ke sekolah-sekolah atau melalui mata pelajaran yang membahas tentang pajak tersebut sebagai suatu proses belajar membimbing siswa ke arah perkembangan kepribadian sosial yang memiliki sikap bertanggung jawab dan efektif dalam lingkungannya (Septiyani \& Putranti, 2013). Ketika siswa didik dari sejak dini telah mengerti tentang tanggung jawabnya kepada negara, maka akan timbul niat dalam diri siswa didik untuk menjadi warga negara yang taat dalam membayar pajak suatu saat nanti. Hal ini sejalan dengan penelitian yang dilakukan oleh Yulia et al (2020) yang menyatakan bahwa sosialisasi perpajakan berpengaruh positif terhadap kepatuhan pajak, akan tetapi bertolak belakang dengan hasil penelitian yang dilakukan oleh Winerungan (2013) yang mengungkapkan bahwa sosialisasi perpajakan berpengaruh negatif terhadap kepatuhan pajak.

Sosialisasi perpajakan kepada siswa didik akan mampu menumbuhkan kesadaran dalam diri siswa didik. Penyuluhan tentang

$\begin{array}{llll}\begin{array}{l}\text { Perolehan } \\ \text { Pajak }\end{array} & \begin{array}{l}\text { Target } \\ \mathbf{2 0 1 9}\end{array} & \begin{array}{l}\text { Realisasi } \\ \mathbf{2 0 1 9}\end{array} & \text { Pertumbuhan } \\ \begin{array}{l}\text { Daerah } \\ \begin{array}{l}\text { Istimewa } \\ \text { Yogyakarta }\end{array}\end{array} & \text { Rp 6,1 T } & \text { Rp 1,8 T } & 2,38 \% \\ \text { (DIY) } & & & \\ \text { Nasional } & \text { Rp 1.577 T } & \operatorname{Rp~500~T~} & 2,85 \%\end{array}$

pajak ini menjadikan siswa didik mengerti 
ISSN : $2406-7415$

E-ISSN : $2655-9919$

JURNAL AKUNTANSI DAN BISNIS KRISNADWIPAYANA

DOI: http://dx.doi.org/10.35137/jabk.v8i1.486

bahwa pendapatan terbesar negara berasal dari sektor pajak, sehingga nantinya siswa didik harus taat dalam membayar pajak ketika telah memiliki penghasilan. Siswa didik juga akan mengerti bahwa membayar pajak merupakan kewajiban kenegaraan yang harus dipenuhi sebagai anggota dari organisasi negara yang telah diberikan perlindungan dan fasilitas (Wulandari, 2015). Hal ini sejalan dengan penelitian yang dilakukan oleh Sari \& Saryadi (2018) yang mengungkapkan bahwa sosialisasi perpajakan berpengaruh positif terhadap kesadaran pajak, akan tetapi hasil penelitian ini berbeda dengan yang dilakukan oleh oleh Herryanto \& Toly (2013) yang mengungkapkan bahwa kesadaran Wajib Pajak berpengaruh negatif terhadap penerimaan Pajak.

Menumbuhkan niat patuh dalam diri setiap siswa didik agar bisa taat dalam membayar pajak nantinya juga perlu melalui kesadaran pajak tentang pentingnya penerimaan pajak bagi negara. Kesadaran pajak seperti inilah yang diharapkan tumbuh di dalam diri setiap siswa didik melalui upaya sosialisasi perpajakan. Sosialisasi ini akan mempengaruhi niat siswa didik untuk patuh dalam membayar pajak suatu saat nanti, karena siswa didik menyadari betapa pentingnya membayar pajak untuk kemajuan negara. Hal ini sejalan dengan penelitian yang dilakukan oleh Puspita (2016) yang mengungkapkan bahwa adanya pengaruh positif dari sosialisasi perpajakan terhadap kepatuhan pajak melalui kesadaran pajak. Penelitian ini bertolak belakang dengan yang diungkapkan oleh Wulandari (2015) dalam penelitiannya yang menyatakan bahwa tidak ada pengaruh positif dari sosialisasi perpajakan terhadap kepatuhan pajak melalui kesadaran pajak.
Volume 8 Nomor 1 (Januari - April) 2021

Dari penjelasan di atas masih terdapat hasil perbedaan pendapat, sehingga penulis ingin membahas masalah kepatuhan pajak ini lagi. Perbedaan dengan penelitian sebelumnya, variabel dari kepatuhan pajak diperbaharui menjadi niat patuh pajak yang ditujukan terhadap siswa SMA atau sederajat sebagai calon WP. Penelitian ini ingin mengungkap apakah sosialisasi/penyuluhan pajak kepada siswa tingkat SMA sederajat melalui penyuluhanpenyuluhan ke sekolah atau buku-buku pelajaran yang membahas tentang pajak terkhusus siswa didik yang masih berada di tingkat SMA sederajat di DIY, mampu menumbuhkan/meningkatkan kesadaran terhadap pajak dalam diri siswa didik agar dapat mematuhi pajak ketika nanti telah memiliki penghasilan atas pekerjaannya. Pada penelitian ini sosialisasi perpajakan menjadi variabel bebas, niat patuh pajak menjadi variabel terikat, serta kesadaran pajak menjadi variabel intervening.

\section{LANDASAN TEORI}

\section{Niat Patuh Pajak}

Niat adalah instruksi dari individu terhadap dirinya. Mastani \& Khairani (2018) juga mengartikan bahwa timbulnya kemauan yang kuat atas dirinya untuk mengerjakan sesuatu disebut dengan niat. Niat merupakan suatu intensi seseorang dalam mencapai tujuan (Wanarta \& Mangoting, 2014). Pada theory of planned Behavior (TPB) menyatakan bahwa tindakan seseorang muncul karena munculnya niat untuk bertindak, dan keinginan yang dipengaruhi dari tiga unsur yakni behavioral beliefs, normative beliefs, dan control beliefs (Lesmana et al, 2018). 
ISSN : $2406-7415$

E-ISSN : $2655-9919$

JURNAL AKUNTANSI DAN BISNIS KRISNADWIPAYANA

DOI: http://dx.doi.org/10.35137/jabk.v8i1.486

Volume 8 Nomor 1 (Januari - April) 2021

Sosialisasi Pajak

Sosialisasi diartikan sebagai upaya Dirjen Pajak dalam memberikan pemahaman, informasi dan bimbingan terhadap masyarakat seputar perpajakan (Jannah, 2016). Sosialisasi/penyuluhan yang diberikan tidak terpisahkan dengan peningkatan jumlah wajib pajak. Negara \& Supadmi (2020) mengatakan bahwa faktor eksternal dan internal yang mempengaruhi kepatuhan adalah sosialisasi dan pengetahuan pajak.

\section{Kesadaran Pajak}

Kesadaran Wajib Pajak merupakan upaya atau tindakan yang disertai dengan dorongan diri dan kemauan untuk melaksanakan hak dan kewajiban perpajakan sesuai dengan ketentuan peraturan perundang-undangan (Rahayu et al., 2017). Timbulnya kesadaran seseorang dalam membayar pajak adalah ketika peraturan perpajakan tersebut telah diketahui, dihormati, dan dipatuhi. Logikanya adalah ketika peraturan perpajakan tersebut masih terbatas diketahui, maka kesadaran pajak akan tetap rendah. Rendahnya kesadaran pajak diduga disebabkan oleh minimnya pengetahuan dan pemahaman tentang peraturan perpajakan (Rahayu et al, 2017).

\section{Pengaruh Sosialisasi Perpajakan terhadap Niat Patuh Pajak}

Sosialisasi pajak menjadi perihal penting dalam kaitannya dengan menumbuhkan niat patuh pajak, memberikan informasi seputar pajak dan peraturan perpajakan. Naufal \& Setiawan (2018) mengatakan bahwa intensnya informasi yang didapat oleh masyarakat khususnya siswa didik sebagai calon wajib pajak, mampu secara perlahan mengubah pola berfikir siswa didik terhadap pajak, sehingga mendorong siswa agar bisa patuh ketika memenuhi pajaknya suatu saat nanti.

Penelitian sebelumnya yang mendukung hal ini yakni Hafiz \& Saryadi (2018) yang dalam penelitiannya mengungkap bahwa kepatuhan pajak dipengaruhi oleh adanya sosialisasi. Dengan demikian hipotesis yang diambil yakni:

$$
\begin{aligned}
& \mathbf{H}_{1} \text { : Sosialisasi perpajakan } \\
& \text { berpengaruh positif terhadap } \\
& \text { niat patuh pajak }
\end{aligned}
$$

\section{Pengaruh Sosialisasi Perpajakan terhadap Kesadaran Pajak}

Mengingat kesadaran pajak yang masih rendah, sehingga sosialisasi perpajakan erat kaitannya dengan menumbuhkan kesadaran pajak dalam diri masyarakat. Hal ini seperti yang dikatakan oleh Agustini \& Widhiyani (2019) yang menyatakan bahwa kegiatan sosialisasi bertujuan untuk membangun kesadaran masyarakat tentang pentingnya pajak serta menjaring wajib pajak baru. Salah satu faktor yang mempengaruhi rendahnya kesadaran kewajiban perpajakan adalah kurangnya sosialisasi (Herijawati \& Anggraeni, 2018). Oleh sebab itu, sosialisasi tentang perpajakan ini perlu diberikan kepada semua lapisan masyarakat terkhusus siswa didik sebagai calon wajib pajak agar siswa sadar, bahwa penerimaan dari pajak digunakan untuk memajukan negara.

Penelitian sebelumnya yang mendukung hal ini yakni Lesmana et al (2018) yang mengungkapkan bahwa sosialisasi perpajakan berpengaruh signifikan terhadap kesadaran pajak. Dengan demikian hipotesis yang diambil adalah: 
ISSN : $2406-7415$

E-ISSN : $2655-9919$

JURNAL AKUNTANSI DAN BISNIS KRISNADWIPAYANA

DOI: http://dx.doi.org/10.35137/jabk.v8i1.486

Volume 8 Nomor 1 (Januari - April) 2021
$\mathbf{H}_{2}$ : Sosialisasi
perpajakan
mempengaruhi secara positif terhadap kesadaran pajak.

\section{Pengaruh Kesadaran Pajak terhadap Niat Patuh Pajak}

Membangun kesadaran pajak dalam diri siswa didik adalah salah satu cara yang tepat untuk menumbuhkan niat patuh terhadap pajak dalam diri siswa. Ketika siswa didik memahami kriteria siapa saja yang diwajibkan membayar pajak, maka akan tumbuh kesadaran dalam diri siswa untuk patuh dalam membayar pajak nantinya. Tumbuhnya kesadaran dalam diri siswa didik tentang pajak akan menimbulkan pandangan positif mereka terhadap pelaksanaan fungsi negara oleh pemerintah, sehingga akan menggerakkan siswa untuk menumbuhkan niat patuh pajak dalam dirinya.

Penelitian sebelumnya yang mendukung hal ini yakni Andreas \& Savitri (2015) yang mengungkapkan bahwa kesadaran pajak berpengaruh positif terhadap kepatuhan pajak. Dengan demikian hipotesis yang diambil adalah:

$\mathbf{H}_{3}$ : Kesadaran pajak mempengaruhi secara positif terhadap niat patuh pajak

\section{Pengaruh Sosialisasi Perpajakan terhadap Niat Patuh Pajak melalui Kesadaran Pajak}

Sosialisasi perpajakan menjadi hal penting dalam upaya menumbuhkan kesadaran tentang pajak dalam diri siswa didik. Hal ini seperti yang dijelaskan oleh Dharma \& Suardana (2014) bahwa sosialisasi menjadi salah satu faktor yang mempengaruhi kepatuhan dalam membayar pajak. Dengan meningkatnya kesadaran pajak melalui sosialisasi, diharapkan dapat menumbuhkan niat patuh pajak siswa secara sukarela (Puspita, 2016). Keberadaan variabel kesadaran sebagai variabel intervening ini diyakinkan dapat mendukung variabel sosialisasi perpajakan untuk mempengaruhi secara positif variabel niat patuh pajak.

Penelitian sebelumnya yang mendukung hal ini yakni Puspita (2016) yang mengungkapkan bahwa sosialisasi perpajakan berpengaruh terhadap kepatuhan pajak melalui kesadaran pajak.

$\begin{aligned} \mathbf{H}_{4}: & \text { Sosialisasi projakan } \\ & \text { berpengaruh positif terhadap } \\ & \text { niat patuh pajak melalui } \\ & \text { kesadaran pajak. }\end{aligned}$

\section{Gambar 1. Kerangka pikir penelitian}

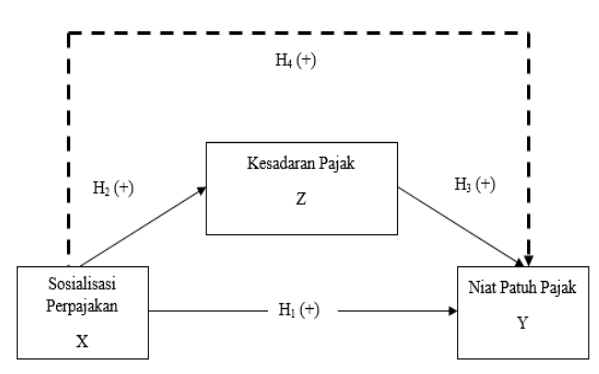

\section{METODE PENELITIAN}

Populasi pada penelitian ini yaitu siswa SMA atau sederajat yang ada di Daerah Istimewa Yogyakarta sebagai calon wajib pajak. Sampel dalam penelitian ini menggunakan tehnik convenience sampling. Jumlah sampel yang digunakan sebanyak 82, yaitu calon WP siswa sekolah tingkat SMA atau sederajat di Daerah Istimewa Yogyakarta.

Instrumen yang digunakan berupa kuesioner atas seluruh pernyataan dari 
ISSN : $2406-7415$

E-ISSN : $2655-9919$

JURNAL AKUNTANSI DAN BISNIS KRISNADWIPAYANA

DOI: http://dx.doi.org/10.35137/jabk.v8i1.486

indikator setiap variabel. Sebelumnya penelitian ini melakukan uji tes awal penelitian sebelum penelitian sesungguhnya dilakukan atau biasa yang disebut dengan uji pilot test. Pilot test yang dilakukan mengambil 30 orang informan dari siswa tingkat SMA sederajat di Daerah Istimewa Yogyakarta.

Variabel dalam penelitian ini menggunakan skala likert 1-5. Responden akan memilih salah satu jawaban dari pernyataan atau pertanyaan yang diberikan. Untuk pernyataan positif diberi skor dari sangat setuju 5 poin, skor setuju 4 poin, skor netral 3 poin, skor tidak setuju 2 poin, dan skor tidak setuju 1 poin. Poin sebaliknya diberikan ketika pernyataan negatif yaitu mulai dari skor sangat setuju 1 poin, skor setuju 2 poin, skor netral 3 poin, skor tidak setuju 4 poin dan skor sangat tidak setuju 5 poin.

Pada penelitian ini, software yang digunakan dalam olah data adalah SmartPLS 3.0 .

\section{Definisi Operasional Variabel Sosialisasi Perpajakan (X)}

Sosialisasi/penyuluhan perpajakan yaitu membagikan pengertian terkait perpajakan dengan tujuan menambah pemahaman pajak kepada siswa didik sebagai calon wajib pajak agar paham tentang pajak dan tata caranya untuk memudahkan siswa jika suatu saat akan memenuhi kewajibannya (Septiani et al., 2018).

Instrumen dalam menilai sosialisasi perpajakan diperoleh dari Septiani et al (2018) dan telah dimodifikasi yang mencakup indikator pengarahan/penyuluhan, diskusi langsung antara fiskus dengan siswa didik sebagai calon wajib pajak, fiskus memberikan
Volume 8 Nomor 1 (Januari - April) 2021

informasi langsung kepada siswa didik sebagai calon wajib pajak, baik melalui penyuluhan ke sekolah atau buku-buku pelajaran yang membahas seputar pajak, pemasangan papan reklame pada tempat strategis, serta internet (website DJP) dan sosial media Dirjen Pajak seperti instagram dan twitter.

\section{Definisi Operasional Variabel Niat Patuh Pajak (Y)}

Niat diartikan menjadi suatu kecenderungan dan keputusan. Kecenderungan ialah kemauan seseorang mematuhi atau tidak terhadap pemenuhan kewajiban pajaknya, sedangkan keputusan adalah langkah yang diambil oleh seorang individu untuk patuh atau tidak dengan aturan pajak yang ada (Wanarta \& Mangoting, 2014).

Instrumen dalam menilai variabel niat patuh pajak diperoleh atas penelitian dari Sukmawati (2017) diantaranya indikator kecenderungan untuk berperilaku patuh pajak dan keputusan untuk taat pajak.

\section{Definisi Operasional Variabel Kesadaran Pajak (Z)}

Kesadaran Wajib Pajak merupakan upaya atau tindakan yang disertai dengan dorongan diri dan kemauan untuk melaksanakan hak dan kewajiban perpajakan sesuai dengan ketentuan peraturan perundang-undangan (Rahayu et al., 2017).

Instrumen yang digunakan untuk mengukur tingat kesadaran pajak calon wajib pajak diambil dari Rahayu et al (2017) yang telah dimodifikasi terdiri dari 5 (lima) indikator, yaitu mengetahui fungsi pajak, memahami hak dan kewajiban seseorang jika telah menjadi wajib pajak, mengerti cara menghitung pajak yang benar, 
ISSN : $2406-7415$

E-ISSN : $2655-9919$

DOI: http://dx.doi.org/10.35137/jabk.v8i1.486

JURNAL AKUNTANSI DAN BISNIS KRISNADWIPAYANA

mengetahui cara membayar pajak, dan mengetahui cara melaporkan pajak

\section{HASIL PENELITIAN DAN PEMBAHASAN}

\begin{tabular}{|c|c|c|c|c|c|c|c|}
\hline \multicolumn{8}{|c|}{ Statistik Deskriptif } \\
\hline \multicolumn{8}{|c|}{ Tabel 2. Hasil analisis statistik deskriptif } \\
\hline & $\mathrm{N}$ & Min & Max & Sum & Mean & & $\begin{array}{l}\text { Std. } \\
\text { Deviation }\end{array}$ \\
\hline & Stat. & Stat. & Stat. & Stat. & Stat. & $\begin{array}{l}\text { Std. } \\
\text { Error }\end{array}$ & Stat. \\
\hline SP & 82 & 17 & 30 & 1954 & 23,83 &, 318 & 2,879 \\
\hline NPP & 82 & 12 & 20 & 1305 & 15,91 &, 219 & 1,983 \\
\hline KP & 82 & 24 & 40 & 2625 & 32,01 & ,436 & 3,949 \\
\hline lid & 82 & & & & & & \\
\hline
\end{tabular}

Sumber: Data primer diolah, 2020

Atas hasil analisis statistik deskriptif pada tabel di atas membuktikan bahwa sosialisasi perpajakan (X) untuk 82 informan nilai paling kecilnya yakni 17 dan nilai paling besar adalah 30. Rata-rata jawaban setuju untuk pernyataan yang berhubungan dengan sosialisasi perpajakan yakni 23,83 dan standar deviasinya 2,879.

Niat Patuh Pajak (Y) dari 82 informan nilai paling kecilnya yakni 12 dan nilai paling besar 20. Rata-rata jawaban setuju pada pernyataan yang berhubungan dengan pemahaman pajak yakni 15,91 dan standar deviasinya 1,983.

Kesadaran Pajak $(Z)$ dari 82 informan nilai paling kecilnya yakni 24 dan nilai paling besar adalah 40. Rata-rata jawaban setuju di pernyataan yang berhubungan
Volume 8 Nomor 1 (Januari - April) 2021

dengan kesadaran pajak yakni 32,01 dan standar deviasinya 3,949 .

\section{Uji Validitas, Uji Reliabilitas}

Atas hasil pengujian validitas terungkap bahwa keseluruhan item pernyataan didalam kuesioner dinyatakan valid. Dibuktikan dari nilai loading factor $(>0,50)$. Selain itu, hasil uji reliabilitas membuktikan bahwa keseluruhan variabel dinyatakan reliable yang ditunjukkan oleh nilai composite reliability $(>0,7)$ dan nilai cronbach's alpha $(>0,60)$.

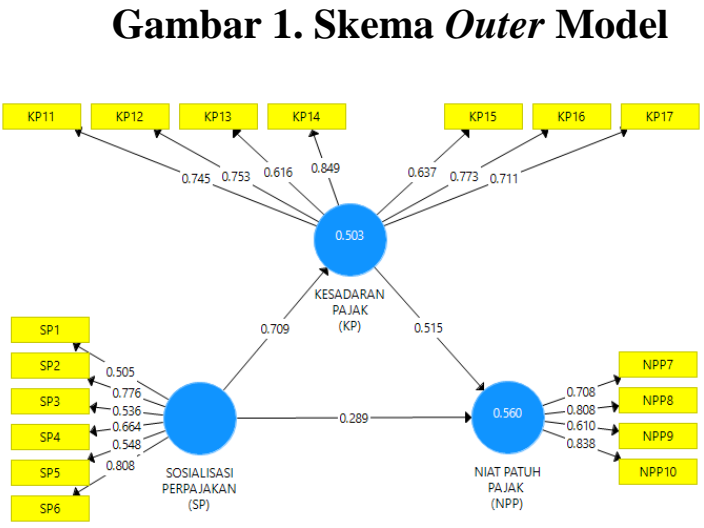

\section{Gambar 2. Skema Inner Model}

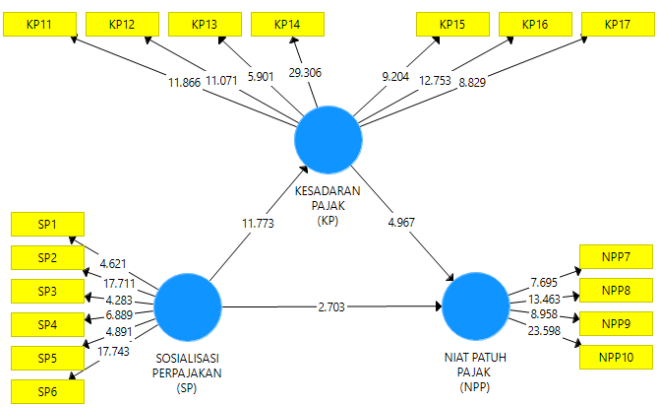

Sumber: Data primer diolah, 2020

Tabel 3. Hasil uji R-Square

\begin{tabular}{cc}
\hline Variabel & R-Square \\
\hline KP & 0,503
\end{tabular}


ISSN : $2406-7415$

E-ISSN : $2655-9919$

JURNAL AKUNTANSI DAN BISNIS KRISNADWIPAYANA

DOI: http://dx.doi.org/10.35137/jabk.v8i1.486

Volume 8 Nomor 1 (Januari - April) 2021

\begin{tabular}{ccc}
\hline & Variabel & $\begin{array}{c}\text { R- } \\
\text { Square }\end{array}$ \\
\hline & KP & 0,503 \\
& NPP & 0,560 \\
\hline NPP & \multicolumn{2}{c}{0,560}
\end{tabular}

Sumber: Data primer diolah, 2020

Atas hasil pengujian R-square di atas dapat dipahami bahwa nilai R-square pada variabel NPP memiliki nilai 0,560 yang artinya termasuk pada kategori kuat. Selain itu nilai R-square untuk variabel KP 0,503 yang artinya termasuk juga pada kategori kuat.

Tabel 4. Nilai path coefficients

\begin{tabular}{|c|c|c|c|c|c|}
\hline & $\begin{array}{l}\text { Original } \\
\text { Sample } \\
\text { (O) }\end{array}$ & $\begin{array}{l}\text { Sample } \\
\text { Mean } \\
\text { (M) }\end{array}$ & $\begin{array}{l}\text { Standart } \\
\text { Error } \\
\text { (STERR) }\end{array}$ & $\begin{array}{l}\text { T Statistic } \\
\text { (O/STERR) }\end{array}$ & $\begin{array}{l}P \text { - } \\
\text { Values }\end{array}$ \\
\hline $\begin{array}{l}\text { SP => } \\
\text { NPP }\end{array}$ & 0,289 & 0,279 & 0,100 & 2,886 & 0,004 \\
\hline $\mathrm{SP} \Rightarrow \mathrm{KP}$ & 0,709 & 0,726 & 0,060 & 11,796 & 0,000 \\
\hline $\begin{array}{l}\mathrm{KP}=> \\
\mathrm{NPP}\end{array}$ & 0,515 & 0,535 & 0,102 & 5,033 & 0,000 \\
\hline $\begin{array}{l}S P \Rightarrow K P \\
\Rightarrow N P P\end{array}$ & 0,365 & 0,389 & 0,084 & 4,349 & 0,000 \\
\hline
\end{tabular}

Sumber: Data primer diolah, 2020

Atas hasil nilai path coefficients di atas membuktikan kalau hubungan antara SP dan NPP yakni signifikan ditandai dengan nilai T-statistik 2,886 (>1,96). Nilai original sample estimate yakni positif 0,289 yang membuktikan hubungan antara SP dan NPP adalah positif. Oleh sebab itu hipotesis $\mathrm{H} 1$ pada penelitian ini mengungkap kalau sosialisasi perpajakan ternyata mempunyai pengaruh yang positif pada niat patuh pajak.

Hubungan antara SP dan KP yakni signifikan ditandai dengan nilai $\mathrm{T}$-statistik
11,796 (>1,96). Nilai original sample estimate yakni positif 0,709 yang membuktikan hubungan antara SP dan KP adalah positif. Oleh karena itu hipotesis $\mathrm{H} 2$ pada penelitian ini menyatakan sosialisasi perpajakan berpengaruh positif terhadap kesadaran pajak.

Hubungan antara KP dan NPP adalah signifikan ditandainya nilai $\mathrm{T}$-statistik 5,033 $(>1,96)$. Nilai original sample estimate yaitu positif 0,515 sehingga membuktikan adanya hubungan positif antara KP dan NPP. Oleh karena itu hipotesis $\mathrm{H} 3$ pada penelitian ini menyatakan kesadaran pajak berpengaruh positif terhadap niat patuh pajak.

Hubungan antara SP dan NPP melalui KP yakni signifikan ditandai dengan nilai $\mathrm{T}$ statistik 4,349 $(>1,96)$. Nilai original sample estimate yaitu positif 0,365 yang membuktikan hubungan antara SP dan NPP melalui KP adalah positif. Oleh karena itu, hipotesis $\mathrm{H} 4$ pada penelitian ini menyatakan sosialisasi perpajakan mempunyai pengaruh yang positif pada niat patuh pajak melalui kesadaran pajak.

\section{Pengaruh Sosialisasi Perpajakan terhadap Niat Patuh Pajak}

Berdasarkan pengujian Hipotesis 1 menunjukkan bahwa adanya hubungan yang positif antara sosialisasi perpajakan dengan niat patuh pajak. Hal ini dibuktikan dengan nilai T-statistic 2,886 $(>1,96)$ dan memiliki nilai original sample estimate 0,289. Hasil penelitian ini serupa dengan yang ditemukan oleh Hafiz \& Saryadi (2018) bahwa adanya pengaruh positif antara sosialisasi perpajakan dengan kepatuhan pajak. Oleh karena itu, dengan adanya sosialisasi perpajakan diharapkan dapat menumbuhkan niat patuh dalam diri siswa untuk mematuhi kewajiban perpajakan. Dengan demikian, 
ISSN : $2406-7415$

E-ISSN : $2655-9919$

JURNAL AKUNTANSI DAN BISNIS KRISNADWIPAYANA

DOI: http://dx.doi.org/10.35137/jabk.v8i1.486

dapat disimpulkan bahwa semakin tinggi kegiatan sosialisasi yang diberikan kepada siswa didik, maka semakin tinggi pula niat siswa untuk mematuhi pajak ketika nanti telah memiliki penghasilan. Sehingga pada hipotesis petama ini diterima.

\section{Pengaruh Sosialisasi Perpajakan terhadap Kesadaran Pajak}

Hasil pengujian Hipotesis 2 menunjukkan bahwa adanya hubungan yang positif antara sosialisasi perpajakan dengan Kesadaran pajak. Hal ini dibuktikan dengan nilai T-statistic sebesar 11,796 (>1,96) dan memiliki nilai original sample estimate 0,709 . Hasil penelitian ini serupa dengan yang ditemukan oleh Lesmana et al (2018) bahwa sosialisasi perpajakan berpengaruh positif terhadap kesadaran pajak. Oleh karena itu, kesadaran pajak akan terbentuk dalam diri siswa didik apabila siswa telah mengikuti sosialisasi perpajakan, dan memahami isi dari sosialisasi yang telah dilakukan oleh Dirjen Pajak. Dengan demikian, dapat disimpulkan bahwa semakin tinggi kegiatan sosialisasi yang diberikan kepada siswa didik, maka semakin tinggi kesadaran siswa didik tentang betapa pentingnya taat pajak. Sehingga pada hipotesis kedua ini diterima.

\section{Pengaruh Kesadaran Pajak terhadap Niat Patuh Pajak}

Hasil pengujian Hipotesis 3 menunjukkan bahwa adanya hubungan yang positif antara kesadaran pajak dengan niat patuh pajak. Hal ini dibuktikan dengan nilai T-statistic 5,033 (>1,96) dengan nilai original sample estimate 0,515. Hasil penelitian ini serupa dengan yang ditemukan
Volume 8 Nomor 1 (Januari - April) 2021

oleh Andreas \& Savitri (2015) yang mengungkapkan bahwa kesadaran pajak berpengaruh positif terhadap kepatuhan pajak. Oleh karena itu, kesadaran siswa didik tentang pajak akan meningkat ketika timbulnya persepsi positif terhadap pajak. Dengan demikian, semakin tinggi kesadaran pajak yang dimiliki siswa didik maka akan semakin tinggi pula niat siswa untuk mematuhi pajak nantinya. Sehingga pada hipotesis ketiga ini diterima.

\section{Pengaruh Sosialisasi Perpajakan terhadap Niat Patuh Pajak melalui Kesadaran Pajak}

Hasil pengujian Hipotesis 4 menunjukkan bahwa adanya hubungan yang positif dari sosialisasi perpajakan terhadap niat patuh pajak melalui kesadaran pajak. Hal ini dibuktikan dengan nilai T-statistik 4,349 (>1,96) dan memiliki nilai original sample estimate 0,365 . Hasil penelitian ini serupa dengan yang ditemukan oleh Puspita (2016) yang mengungkapkan bahwa sosialisasi perpajakan berpengaruh positif terhadap kepatuhan pajak melalui perantara kesadaran pajak. Oleh karena itu, keberadaan variabel kesadaran pajak sebagai variabel intevening, tidak menjadi pengaruh untuk variabel sosialisasi perpajakan dalam mempengaruhi niat patuh pajak siswa. Hal ini karena, pada hipotesis pertama sosialisasi perpajakan berpengaruh positif terhadap kepatuhan pajak. Sehingga, dapat disimpulkan bahwa walaupun tidak ada variabel kesadaran pajak sebagai variabel intervening, maka hanya dengan sosialisasi perpajakan sudah mampu mempengaruhi secara positif variabel niat patuh pajak. Dengan demikian, hipotesis keempat ini diterima. 
ISSN : $2406-7415$

E-ISSN : $2655-9919$

JURNAL AKUNTANSI DAN BISNIS KRISNADWIPAYANA

DOI: http://dx.doi.org/10.35137/jabk.v8i1.486

Volume 8 Nomor 1 (Januari - April) 2021

\section{KESIMPULAN DAN SARAN}

\section{Kesimpulan}

Atas hasil penelitian yang dilakukan kepada 82 informan yaitu siswa didik tingkat sekolah SMA sederajat di Daerah Istimewa Yogyakarta, maka bisa disimpulkan bahwa terdapat pengaruh positif dari sosialisasi perpajakan dengan kesadaran pajak dan niat patuh pajak, kesadaran pajak juga mempunyai pengaruh yang positif pada niat patuh pajak, serta sosialisasi perpajakan juga mempunyai pengaruh yang positif terhadap niat patuh pajak melalui kesadaran pajak.

\section{Saran}

\section{Bagi Pihak DJP}

Berdasarkan hasil penelitian membuktikan bahwa adanya pengaruh yang positif dari sosialisasi terhadap niat patuh pajak melalui kesadaran pajak yang menjadi variabel intervening pada studi kasus siswa SMA atau sederajat di Daerah Istimewa Yogyakarta sebagai calon WP. Gerakan yang dapat dilakukan oleh DJP adalah memberikan penyuluhan tentang pajak terkhusus kepada siswa SMA atau sederajat, sebab tidak dalam waktu yang lama lagi setiap dari siswa didik ada yang tidak melanjutkan ke jenjang perkuliahan, yaitu langsung bekerja. Sehingga perlu adanya pemberian kesadaran tentang pajak kepada siswa agar menumbuhkan niat patuh dalam membayar pajak pada saat nanti sudah bekerja khususnya di wilayah Kota Yogyakarta.

\section{Bagi Peneliti Beriikutnya}

Peneliti berikutnya dapat menambahkan variabel yang baru atau berbeda selain dari variabel sosialisasi perpajakan, kesadaran pajak, dan niat patuh pajak yang dipakai pada penelitian ini. Selain itu diharapkan untuk peneliti berikutnya bisa menambah sampel dan meluaskan ruang lingkup penelitian.

\section{DAFTAR PUSTAKA}

Cahya Pekerti, T., Wilopo, \& Maulinahardi R, M. (2015). Pengaruh Sosialisasi Perpajakan terhadap Pemahaman Wajib Pajak yang Mendukung Kepatuhan Wajib pajak. Jurnal Perpajakan, 7(1), $1-10$.

Faris Naufal, M., \& Setiawan, P. E. (2018). Pengaruh Sosialisasi Perpajakan, Pemahaman Prosedur Perpajakan, Umur, Jenis Pekerjaan terhadap Kepatuhan Wajib Pajak Orang Pribadi. E-Jurnal Akuntansi, 25, 241.

Hafiz, M. (2018). Pengaruh Sosialisasi Wajib Pajak terhadap Kepatuhan Wajib Pajak melalui Pemahaman Wajib Pajak sebagai Variabel Intervening (Studi Empiris Kebijakan Amnesti Pajak pada UMKM di KPP Pratama Semarang Tengah Dua). Universitas Dioponegoro, 7(3).

Jessica Novia Susanto. (2013). Pengaruh Persepsi Pelayanan Aparat Pajak, Persepsi Pengetahuan Wajib Pajak, dan Persepsi Pengetahuan Korupsi terhadap Kepatuhan. Calyptra: Jurnal Ilmiah Mahasiswa Universitas Surabaya, 2(1), 1-17.

Lesmana, D., Panjaitan, D., \& Maimunah, M. (2018). Tax Compliance ditinjau dari Theory of Planned Behavior (TPB): Studi Empiris pada Wajip Pajak 
ISSN : $2406-7415$

E-ISSN : $2655-9919$

JURNAL AKUNTANSI DAN BISNIS KRISNADWIPAYANA

DOI: http://dx.doi.org/10.35137/jabk.v8i1.486

Volume 8 Nomor 1 (Januari - April) 2021

Orang Pribadi dan Badan yang Terdaftar Pada KPP di Kota Palembang. InFestasi.

Lubis, B. P. (2019). The Effect of Understanding Taxation Regulations, Understanding Tax Accounting, Tax Planning and Application Modern Tax Administration System on Tax Compliance ( Survey of Taxpayers Registered at Tax Office Cengkareng Jakarta ). 8(9), 2018-2020.

Nurkhin, A., Novanty, I., Muhsin, M., \& Sumiadji, S. (2018). The Influence of Tax Understanding, Tax Awareness and Tax Amnesty toward Taxpayer Compliance. Jurnal Keuangan Dan Perbankan, 22(2).

Purba, B. P. (2016). Pengaruh Sosialisasi Perpajakan dan Pemahaman Perpajakan terhadap Kepatuhan Wajib Pajak Orang Pribadi dengan Pelayanan Fiskus Sebagai Variabel Moderating di Kantor Pelayanan Pajak Jakarta Kembangan. Akuntansi Perpajakan, 1(2), 29-43.

Sari, I. K., \& Saryadi. (2019). Pengaruh Sosialisasi Perpajakan dan Pengetahuan Perpajakan terhadap Kepatuhan Wajib Pajak melalui Kesadaran Wajib Pajak sebagai Variabel Intervening (Studi Kasus Pelaku UMKM yang Terdaftar di KPP Pratama Semarang Timur). Jurnal Ilmu Administrasi Bisnis.

Septiani, E., Susyanti, J., \& Rachmat, A. (2018). Pengaruh Sosialisasi Perpajakan, Pengetahuan Tarif Perpajakan, dan Pemahaman Perpajakan terhadap Kepatuhan Wajib Pajak (Studi pada UMKM yang Terdaftar sebagai Wajib Pajak di Kantor Pelayanan Pajak Pratama Malang Selatan). E - Jurnal Riset Manajemen, 126-138.
Septiyani, N., \& Putranti, T. M. (2013). Penguatan Pengetahuan Perpajakan bagi Siswa Didik Menuju Voluntary Tax Compliance yang Berkelanjutan (Studi Kasus Sekolah Menengah Pertama dan Sederajat di Provinsi DKI Jakarta). Hal 1-20.

Wanarta, F. E., \& Mangoting, Y. (2014). Pengaruh Sikap Ketidakpatuhan Pajak, Norma Subjektif, dan Kontrol Perilaku yang Dipersepsikan terhadap Niat Wajib Pajak Orang Pribadi untuk Melakukan Penggelapan Pajak. Tax \& Accounting Review, 4(1), 138.

Wardani, D. K., Kartikasari, F. Pengaruh Sosialisasi PP 23/2018 terhadap Kepatuhan Wajib Pajak UMKM dengan Pemahaman Wajib Pajak sebagai Variabel Intervening. 5(1), 116.

Wardani, D. K., \& Wati, E. (2018). Pengaruh Sosialisasi Perpajakan terhadap Kepatuhan Wajib Pajak dengan Pengetahuan Perpajakan sebagai Variabel Intervening (Studi pada Wajib Pajak Orang Pribadi di KPP Pratama Kebumen) Riset Akuntansi Dan Manajemen, 7(1).

Winerungan, O. L. (2013). Sosialisasi Perpajakan, Pelayanan Fiskus dan Sanksi Perpajakan terhadap Kepatuhan WPOP Di Kpp Manado Dan Kpp Bitung. Jurnal Riset Ekonomi, Manajemen, Bisnis Dan Akuntansi, 1(3), 960-970.

Wulandari, T., A., \& Ilham, E. (2015). Pengaruh Sosialisasi Perpajakan, Pengetahuan Perpajakan, dan Kualitas Pelayanan terhadap Kepatuhan Wajib Pajak dengan Kesadaran Wajib Pajak sebagai Variabel Intervening (Studi Pada Kantor Pelayanan Pajak Pratama 
ISSN : $2406-7415$

E-ISSN : 2655 - 9919

JURNAL AKUNTANSI DAN BISNIS KRISNADWIPAYANA

DOI: http://dx.doi.org/10.35137/jabk.v8i1.486

Volume 8 Nomor 1 (Januari - April) 2021

Pekanbaru Senapelan). Jurnal Online

Mahasiswa Fakultas Ekonomi

Universitas Riau, 2(2).

www.krjogja.com. Diakses 28 November 2020 
ISSN : $2406-7415$

E-ISSN : 2655 - 9919

JURNAL AKUNTANSI DAN BISNIS KRISNADWIPAYANA

DOI: http://dx.doi.org/10.35137/jabk.v8i1.486

Volume 8 Nomor 1 (Januari - April) 2021 